\title{
Electron Microscopy of Cr/Silica Catalyst for Ethylene Polymerization
}

\author{
R.-J. Liu and P. A. Crozier
}

Center for Solid State Science, Arizona State University, Tempe, AZ 85287

The Phillips $\mathrm{Cr}$ /silica catalyst is one of the most important commercial catalysts for the polymerization of ethylene [1]. It has been extensively studied and yet even today there is still debate about the fragmentation mechanism of the catalysts and the valence state of the active chromium sites. We will use environmental transmission electron microscopy (E-TEM) to observe the polymer growth on the nanometer scale. We will will also determine the valence state of the active chromium sites. Here we report some preliminary results on the ex-situ catalysts characterization and associated technique development.

The catalyst was prepared by impregnating the 955 silica support (pore volume 1.62 c.c./g and surface area $310 \mathrm{~m}^{2} / \mathrm{g}$ ) with chromium acetate and then calcining in dry air at $825^{\circ} \mathrm{C}$ for 4 hours to activate. The microstructure (fig. 1) of the $\mathrm{Cr} /$ silica catalyst (with $0.5 \mathrm{wt} \% \mathrm{Cr}$ loading) before activation was determined with a Phillips CM 200 FEG transmission electron microscope. Each microparticle of the catalyst is an agglomeration of small silica particles with an average diameter of about $10 \mathrm{~nm}$. The sample appeared to be amorphous everywhere. No crystalline area, indicating clustering of the chromium compound particles, was found indicating the presence of highly dispersed $\mathrm{Cr}$. It does not appear to be any different from the microstructure of the plain silica, as would be expected.

We will use the technique of electron energy loss spectroscopy (EELS) to determine the oxidation state of $\mathrm{Cr}$ during catalysis.[2] In our research, it is necessary to determine the oxidation state of very small amounts of $\mathrm{Cr}$ in the presence of a large $\mathrm{O}$ edge from the underlying silica support. We have compared three different methods for determining the $\mathrm{Cr}$ valence states from two $\mathrm{Cr}$ standards of known oxidation state: $\mathrm{Cr}_{2} \mathrm{O}_{3}\left(\mathrm{Cr}^{+3}\right)$ and $\mathrm{PbCrO}_{4}\left(\mathrm{Cr}^{+6}\right)$. Energy-loss spectra were acquired in a Phillips 430 E-TEM operating at an accelerating voltage of $300 \mathrm{kV}$. The spectra are shown in fig. 2 with the first peaks of the oxygen $\mathrm{K}$ edge aligned with each other.

Table 1 shows that $\Delta \mathrm{E}_{1}$ and $\Delta \mathrm{E}_{2}$ (the position of the maximum intensities of the $\mathrm{Cr}-\mathrm{L}_{2,3}$ absorption edges relative to the first peak of the $\mathrm{O}-\mathrm{K}$ edge) increased by about $4 \mathrm{eV}$ with increasing oxidation state. About $2 / 3$ of this change in $\Delta \mathrm{E}_{1}$ and $\Delta \mathrm{E}_{2}$ was caused by the chemical shift of $\mathrm{Cr}-\mathrm{L}_{2,3}$ edges (2.7 $\mathrm{eV}$ reported by Daulton el al.[3]) and the rest of the change was caused by the chemical shift of the $\mathrm{O}-\mathrm{K}$ edge. The $\mathrm{L}_{3} / \mathrm{L}_{2}$ white-line ratio, i.e. $\mathrm{I}\left(\mathrm{L}_{3}\right) / \mathrm{I}\left(\mathrm{L}_{2}\right)$, was determined after first subtracting an $\mathrm{AE}^{-\mathrm{r}}$ background from beneath both $\mathrm{O}$ and $\mathrm{Cr}$ edges and then subtracting a trapezoidal region from under the $\mathrm{Cr}$ white-line region to make a first order correction for transitions to the continuum states above the thresholds of these edges. The results show that the $\mathrm{I}\left(\mathrm{L}_{3}\right) / \mathrm{I}\left(\mathrm{L}_{2}\right)$ ratio decreases with increased oxidation state. Finally we tried determining the valence state by normalizing the total white-line intensity to the continuum $\mathrm{I}(\mathrm{C})$ in a window $50 \mathrm{eV}$ in width beginning $50 \mathrm{eV}$ past the $\mathrm{L}_{3}$ white line onset. The contribution of $\mathrm{O}$ signal in this normalization window was approximated using the calculated $\mathrm{O}$ energy differential cross-section and subtracted (illustrated in fig. 2). Since the accuracy of this method strongly depends on the quality of both the background subtraction and the calculated differential cross-section, it was believed to cause a 
big error range although the data show that the normalized white-line area increases with increased oxidation state. Therefore the oxidation state of $\mathrm{Cr}$ in the catalyst can be best determined by the chemical shift of $\mathrm{L}_{2,3}$ edges relative to the first peak of $\mathrm{O}-\mathrm{K}$ edge from silica and the ratio of $\mathrm{I}\left(\mathrm{L}_{3}\right) / \mathrm{I}\left(\mathrm{L}_{2}\right)$, integrated-peak intensities. An in-situ polymerization experiment will be performed in an environmental transmission electron microscope (a modified Phillips 430 E-TEM) to observe the evolution in the catalyst microstructure and the chromium oxidation state.

\section{References}

[1] K. H. Theopold, European Journal of Inorganic Chemistry 1 (1998) 15.

[2] D. H. Pearson et al., Phys. Rev. B 47 (1993) 8471.

[3] T. L. Daulton et al., Microscopy and Microanalysis 7 (2001) 470.

[4] Funding was provided by the Dow Chemical Company and the Industrial Associates Program of Arizona State University.
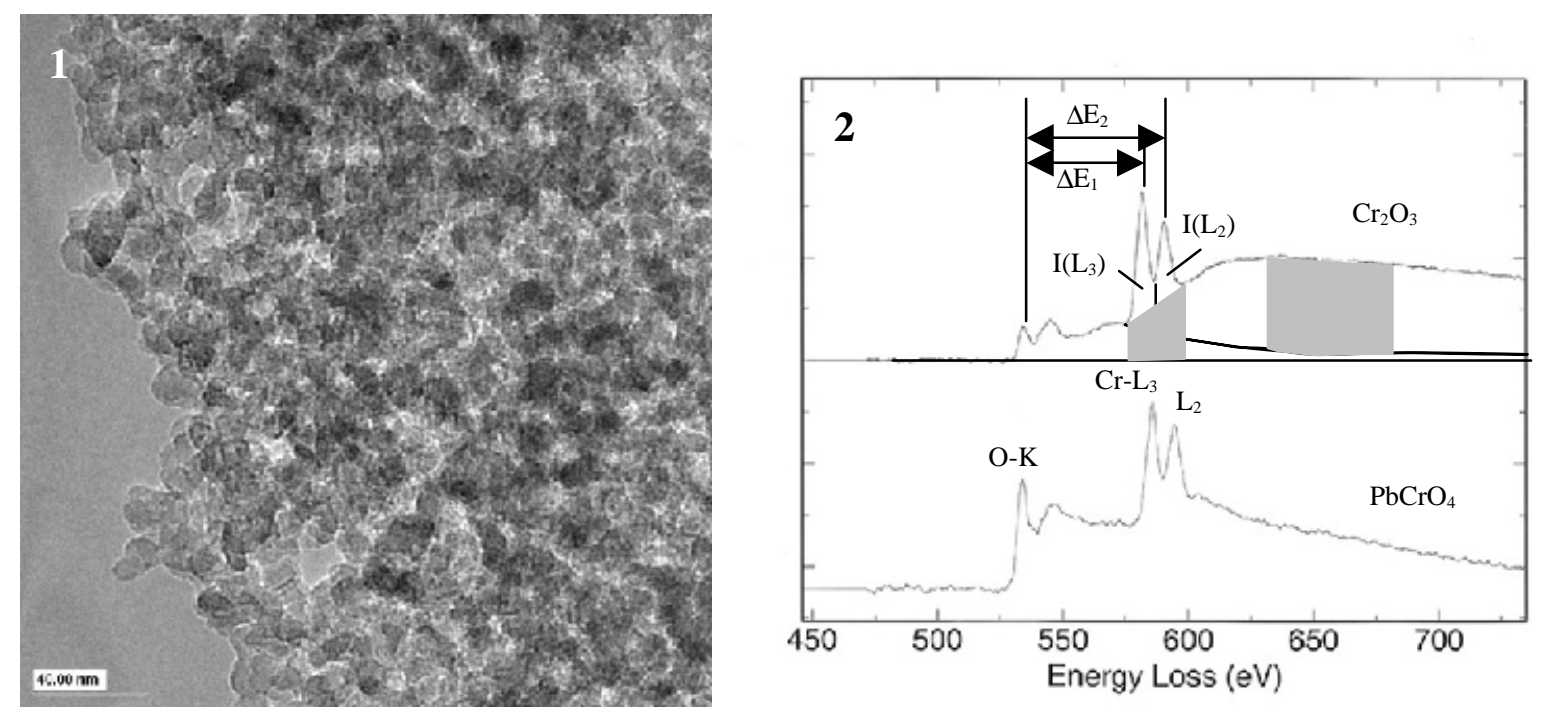

FIG. 1. TEM picture of the $\mathrm{Cr}$ /silica catalyst showing the agglomerationof small $\mathrm{SiO}_{\mathrm{x}}$ particles.

FIG. 2. EELS spectra from $\mathrm{Cr}_{2} \mathrm{O}_{3}\left(\mathrm{Cr}^{+3}\right)$ and $\mathrm{PbCrO}_{4}\left(\mathrm{Cr}^{+6}\right)$, with the first peaks of O-K edge aligned with each other. The method for isolating and normalizing the $\mathrm{Cr}$ whiteline intensities $\mathrm{I}\left(\mathrm{L}_{3}\right)$ and $\mathrm{I}\left(\mathrm{L}_{2}\right)$ is also shown (see text).

Table 1 Results from three EELS processing techniques showing their sensitivity to the oxidation-state-induced change in two $\mathrm{Cr}$ standards, see text.

\begin{tabular}{cccccc}
\hline Compound & $\begin{array}{c}\mathrm{Cr} \\
\text { valence }\end{array}$ & $\begin{array}{c}\Delta \mathrm{E}_{1} \\
(\mathrm{eV})\end{array}$ & $\begin{array}{c}\Delta \mathrm{E}_{2} \\
(\mathrm{eV})\end{array}$ & $\mathrm{I}\left(\mathrm{L}_{3}\right) / \mathrm{I}\left(\mathrm{L}_{2}\right)$ & $\left(\mathrm{I}\left(\mathrm{L}_{3}\right)+\mathrm{I}\left(\mathrm{L}_{2}\right)\right) / \mathrm{I}(\mathrm{C})$ \\
\hline $\mathrm{Cr}_{2} \mathrm{O}_{3}$ & +3 & $47.5+/-0.5$ & $56.0+/-0.5$ & $1.52+/-0.03$ & $0.25+/-0.06$ \\
$\mathrm{PbCrO}_{4}$ & +6 & $51.5+/-0.5$ & $60.5+/-0.5$ & $1.23+/-0.06$ & $1.4+/-0.8$ \\
\hline
\end{tabular}

